\title{
Understanding female adolescent 'runaways' and the implications of their decisions in Tigray, northern Ethiopia
}

\author{
Jone G. Lurgain (MA, MSc) ${ }^{1}$, Carola Eyber (MSc, $\left.\mathrm{PhD}\right)^{2}$
}

\begin{abstract}
Affiliations of author(s)
${ }^{1}$ Institute for Global Health and Development, Queen Margaret University, Edinburgh, UK

${ }^{2}$ Institute for Global Health and Development, Queen Margaret University, Edinburgh, UK
\end{abstract}

Word count: 12,592

Number of references: 48

Running Title: Runaway girls in Ethiopia

\section{Corresponding Author:}

Jone Garcia Lurgain, MA, MSc

Institute for Global Health and Development

Queen Margaret University Drive,

Edinburgh, EH21 6UU, Scotland, UK

Tel: $+44(0) 1314740000$

Mobile: +447864685064

Email: jone.lurgain@gmail.com

Acknowledgements*

*This paper is based on a research funded by Santander Bank Scholarship and the bursary of the Institute for Global Health and Development, at Queen Margaret University, Edinburgh, UK. 


\section{ABSTRACT}

Objective: This study aimed to understand the main factors influencing the decision of adolescent girls to run away from home in Tigray, northern Ethiopia, and to explore the social and cultural construction of female adolescent runaways in this region.

Method: In-depth qualitative interviews with seven runaway adolescent girls and six women married at an early age (11-16 years old) were conducted in Wukro and Mekelle in Tigray to investigate why the girls escaped from home and how communities responded to these decisions.

Results: Findings suggest that the immediate trigger that led all the young participants to run away was to escape an arranged marriage, except in one 'romantic' elopement case. Individual and structural factors, such as child maltreatment and educational aspirations, and new family law respectively, also contributed to the decision to escape.

Conclusion: Adolescent runaways seem to be ignored or normalized within the community in Tigray and, in particular, by its public institutions. This may explain why there are limited services for runaway girls, such as shelters and other forms of support. This lack of social protection structures has left these girls unprotected and exposed to a range of risks, such as early and unwanted pregnancies, labor exploitation, dropping out of school, and transactional sex. To date, this phenomenon of adolescent runaways has remained an invisible issue in Tigray as runaway girls are counted under general migration figures. Further research is needed to explore how this phenomenon is categorized at policy level in order to address runaway girls' needs as defined by them.

KEY WORDS: female adolescent runaways; elopements; arranged marriage; child protection; Ethiopia 


\section{Understanding female adolescent 'runaways' and the implications of their decisions in Tigray, northern Ethiopia}

Common childhood and home experiences such as child abuse and neglect, home instability and poor child-parent relationships among runaway adolescents have been identified across the globe (Ferguson, 2009; Peled \& Cohavi, 2009; Raval, Raval, \& Raj, 2010). However, there are some unique factors contributing to the decision of adolescents to run away in resource-poor countries compared to high resource countries, such as poverty and customary practices. For instance, in poor resource settings in Sub-Saharan Africa and Asia, rural families may arrange their daughters' marriage at an early age because of cultural reasons. For example, it is considered a father's duty to marry his daughter off early in order to protect her from sexual practices which may damage her future marriage prospects, and to secure her future economic needs (Boyden, Pankhurst, \& Tafere, 2012; Molla, 2018). However, it seems that girls are resisting this marriage tradition now more than ever. One of the ways in which adolescent girls resist is by running away from home or eloping with a partner (Ahearn, 2004; Allendorf, 2013; Hart, 2010; Marsden, 2007; Raval et al., 2010). This qualitative study explores experiences and factors influencing the decision of seven girls to escape from home in Tigray, northern Ethiopia, a low resource setting, examining the family context as well as the social and cultural determinants.

The definition of 'runaways' refers to individual decisions made without parental consent by girls who, after running away, found refuge in a relative or neighbour's home or lived on their own, and the concept of 'elopements' as running away for love.

Female adolescent runaways have been addressed from a public health and social problem perspective in the literature. For instance, in the USA, where extensive research has been conducted in the last three decades, homelessness, sexual exploitation, high-risk behavior (e.g. unprotected sex, drug use and survival sex) and poor mental health are identified as the main risks that runaway girls are exposed to (Martinez, 2006; Moskowitz, Stein, \& Lighfoot, 2013; Schaffner, 1999; Tyler, Whitbeck, Hoyt, \& Cauce, 2001). In contrast, studies conducted in low-income settings have often examined girl runaways from anthropological and social change theory perspectives. Research in Asia and Latin America frequently problematizes the runaway girl phenomena as a 'romantic' response (elopement) which emerges from the influence of Western behaviors. It is also seen as a 
quest for independence from authoritative parents and the freedom to be involved in romantic relationships (Allendorf, 2013; Marsden, 2007; Murphy-Graham \& Leal, 2015; Pelaez, 2012; Raval et al., 2010; Sloan, 2008).

In Africa, little research has been conducted about adolescent female runaways and 'romantic' elopements in this context. We found few studies exploring transitions from traditional marriage to modern 'love' relationships and family-related issues in Africa. One of these is an anthropological study (Bertrand-Dansereau \& Clark, 2016) examining early divorce among young couples in Malawi, which captures some eloping girls' accounts and associates these 'romantic' elopements with impulsive and fragile relationships. However, there seems to be a dearth of studies focused on the 'runaway girl' phenomena in many other Sub-Saharan countries.

\section{Runaways in Ethiopia}

In Ethiopia, female adolescent runaways are studied from a migration problem perspective by some scholars (Erulkar, Mekbib, Simie, \& Gulema, 2007; Erulkar \& Muthengi, 2009). It is considered a major driver of migration, alongside other socioeconomic factors, such as poverty and educational aspirations (Boyden et al., 2012; Pankhurst, Tiumelissan, \& Chuta, 2016). Female runaways may also be considered a form of resistance to patriarchal social norms that support gendered practices, such as female child marriage. (Mjaaland, 2004).

In ethnographic studies conducted by Mjaaland $(2004,2013)$ in northwest Tigray on social reproduction and the change in gendered roles of women, adolescent girl runaways are represented as an example of Tigrayan women's resistance against patriarchal social norms, as mentioned above. These girls are demanding to continue their education and are also running away from customary practices, such as arranged early marriages. Rahwa, a young participant interviewed for the research who resisted her parents' decision to marry her off, is an illustrative case study. Mjaaland (2004) narrates that when the first offer of marriage came, at the age of eleven, Rahwa returned the silver cross and ring that young girls customarily receive upon engagement in rural villages. She chose to go to school against her parents' will, and she stated that if they forced her to marry, she would run away (p. 75).

Poverty is identified as another important factor influencing adolescent elopements in Ethiopia. Where dowry and bride-price payment systems are dominant, young couples 
with limited resources tend to elope to circumvent customary marriage payments. In the case of rural girls, elopement is seen as the best choice to get access to a 'better life' in urban areas; it is perceived as a way of avoiding both a forced marriage and being forced to remain in the countryside (Boyden et al., 2012; Pankhurst et al., 2016). Therefore, female adolescent runaways are also associated with rural-urban migration. As mentioned above, in some studies rural girls who escape arranged marriage in Ethiopia are treated as migrants who run away to towns and cities searching for education and jobs to improve their lives (Erulkar et al., 2007; Erulkar \& Muthengi, 2009).

\section{Cultural context: poverty and customary early marriage}

Despite the international standards and national laws relating to age of consent, early marriage is still a common practice in many countries across the globe, with the highest rates in Sub-Saharan Africa. Early marriage in this region must be understood within a context of poverty, gender inequality, cultural taboos against premarital sex for girls, religious beliefs and patriarchal predisposition for controlling female sexuality (Walker, 2012).

In Ethiopia, the 1960 Civil Code specified the minimum legal age of marriage for girls at 15 and for boys at 18. This was revised in the 1995 Ethiopian Constitution (Article 34) where it was established that marriage should be entered into 'only with free and full consent of the intending spouses'. Five years later, the 2000 Revised Family and Criminal Codes defined 18 as a marriageable age, aligning with international standards, such as the 1990 'African Charter on the Rights and Welfare of the Child'. This suggested a minimum age for marriage at 18 years old, consistent with the definition of childhood articulated in the 'Convention on the Rights of the Child' (1989). In the case of the research setting of Tigray, the first revision of the regional Family Law came in 1998 and the Tigrayan Family Law was revised again in 2007 when the marriage age in this region was set to 18 for both girls and boys. However, despite the institution of this new legal marriage age, laws governing marriage are not effectively enforced and it is still common practice for parents to arrange marriages for girls between 13 and 16 years old. This is most common in rural areas of Tigray (Ethiopian Demographic and Health Survey [EDHS], 2016) where around $80 \%$ of its population live with very limited resources (Central Statistical Agency of Ethiopia [CSA], 2007).

Although the forms of marriage practiced in Ethiopia vary depending on the region, 
ethnic group and various socio-economic factors, similar to other Sub-Saharan countries, in rural villages parents typically decide when and whom their daughters will marry. The prospective groom's family appoints an elder to conduct negotiations with the girl's family. After an agreement is reached, gifts are exchanged between families, with the balance of exchange favoring the girl's family. In cases of child marriage, arrangements are made until the child-bride can independently manage a household. This could include practices where the girl lives with the boy's parents or makes periodic visits to the boy's family. Most early marriages do not involve the consent of the bride (Chuta \& Morrow, 2015; Erulkar \& Muthengi, 2009; Pankhurst et al., 2016).

Indeed, as Tadele \& Kifle (2012) and Rode Shewaye Molla (2018) describe, in the context of an extremely patriarchal Ethiopian community, women and girls are socialized to be dependent, obedient, and submissive to patriarchs and elders. "Gender inequality exists in the lives of female children from their childhood to their adulthood. Their rights to freedom, education, health, sex, and decision-making are denied" (Molla, 2018, pp. 191-192). For instance, Tadele \& Kifle (2012) note that Ethiopian girls tend to be closely supervised and, except for schooling, church, work, and other accepted reasons, adolescent girls may be prevented from going out of the home and occupying public space. This is because a high value is placed on the virginity of girls at the time of marriage. Parents urge their daughters to get married at an early age because they are responsible for protecting them from early sexual practices. Virginity, early marriage, and bearing children are the ways female children show their religious purity to the patriarchal community (Molla, 2018). As mentioned above, getting married and bearing children at an early age secures a girl or woman's economic needs. Therefore, to preserve the reputation of the family within the community and to maintain their daughters' economic stability and social inclusion, parents decide to marry their daughters off at an early age (Boyden et al., 2012; Molla, 2018).

This marriage tradition has been reproduced from one generation to another in Tigray and this form of patriarchy, as emphasized by Molla (2018), stifles the voices of women and girls from an early age. However, women's resistance to early arranged marriages seems to be better accepted now than in the past. Adolescent girls resist customary arranged marriages by running away from home and eloping with a partner.

Runaway girls in Ethiopia and across the globe remain unprotected and exposed to a range of risks, such as early and unwanted pregnancies, labor exploitation, dropping out of school, transactional sex relationships (Stoebenau, Heise, Wamoyi, \& Bobrova, 2016) and 
sexually risky behavior (Sharp, 2015). Additionally, in poor resource settings with patriarchal structures and customary practices, runaway girls may also suffer social stigma. They may be socially condemned and neglected for resisting their parents' decision to marry them off (Marsden, 2007; Raval et al., 2010; Sharp, 2015). In rural settings, running away is often considered to be a deviant behavior, especially in those cases of 'romantic' elopements, as discussed later on.

Despite the relevance of the implications of the decision to run away from arranged early marriage, few studies have focused on this problem in Africa. The aim of this qualitative research is not to derive findings that can be generalized, but to provide accounts of the reflections of seven runaway girls in Tigray, Ethiopia. These accounts will enhance an understanding of how individual experiences and factors influence their decisions to leave home at an early age. The study also aims to explore the social constructions of this phenomenon locally, including the perceptions and experiences of six older Ethiopian women married at an early age. Despite the small sample size, this enquiry draws attention to an understudied issue and raises relevant questions for further research and discussion, including the need to examine the experiences of female adolescent runaways from a policy perspective (e.g. migration, public health) in the context of Sub-Saharan Africa.

\section{Methodology}

\section{Research design overview}

This research is an exploratory qualitative study conducted from a social constructivist perspective, emphasizing the relevance of listening to young women and seeking to understand the complex issues from an emic perspective. In-depth semi-structured interviews, key informant interviews, a focused group discussion and field observation were the methods used in order to explore processes, meanings and context (Creswell, 2008, 2013; Maxwell, 2013) surrounding the decisions of the seven young female participants to run away from home. They were also used to explore the social and cultural construction of female adolescent runaways within the community, analyzing the interaction of different generations of women in Tigray, northern Ethiopia.

Moreover, the research team applied the 'legends' research technique (Schoen, 2015) to avoid participants' bias and obtain more detailed accounts. Due to the secretive nature of 
the phenomena of adolescent runaways, and the prohibition of underage marriages, this technique was especially key during the data collection process. The legends technique involves the formulation of impersonal questions and the analysis of stories narrated by participants in the third person. As Schoen (2015) highlights, citing Diane Goldstein's study on AIDS accounts, since legends tend to be stories about what happened to someone else, "the risk of telling is minimal because the narratives take a 'believe it or not' position, opening up discussion but not really requiring that one reveals one's own stance" (Goldstein, 2004, pp. 8-9).

\section{Study participants}

Runaway girls are not easily accessed for research purposes. The secrecy of runaways and the stigma surrounding them, often associated with 'immoral' behaviours (e.g. premarital relationships, prostitution) make this population hard to reach. No official data is available on female adolescent runaways and no out-of-home placements were found in the region of Tigray. Given the characteristics of this population group, the lack of a sample frame and the exploratory nature of the study, we used a purposive selection strategy (Bryman, 2004). This was to intentionally identify young female participants with a specific life experience (running away from home) and who met the selection criteria.

The selection criteria for the young cohort of participants was to be a female younger than 26 years old of the Christian Orthodox faith who ran away from home when she was younger than 16 years old. The participants also needed to meet an additional selection criteria of having not returned home for at least one year after running away. This period of time allowed researchers to analyse not only the support these runaway girls had and how they managed their lives after running away, but also the consequences of their decisions to run away. At the time of the interviews, which were conducted between one and seven years after the young female participants ran away, all of them, except the girl who eloped, declared that they have never returned home.

With the exception of the participant who eloped, the rest of the runaway female participants (6) grew up in rural communities within poor resource households. Whereas the 'eloping girl' left her family home at the age of 17, the rest of the young participants escaped from arranged marriage when they were between 13 and 15 years old. The urban participant who eloped was the youngest sibling, whereas four rural participants were the oldest sibling. Four of the seven girls were orphans of one parent. Currently, four out of 
the seven girl participants were living alone and three with relatives. All of them were combining studies and work (e.g. construction work, domestic work). Most of them had passed Grade 9 at school.

Alongside the seven runaway girls, a second cohort of six older women $(>26$ years old) who married at an early age ( $<16$ years old) were recruited to be interviewed. They also took part in a focus group discussion (FGD) in order to explore social construction and community attitudes toward adolescent female runaways, and to discuss changes that may have occurred across generations. A snowball technique was used to reach these older women participants. This is a classic technique used to identify hard-to-reach populations (Trotter, 2012). Key informant interviews were also undertaken with a Gender Based Violence (GBV) expert of the United Nations Population Fund (UNFPA) in Tigray, and a lecturer in Gender and Development studies in Mekelle University. These interviews helped to inform interview protocols and further analysis.

\section{Data collection}

Data for this study was collected between $10^{\text {th }}$ and $28^{\text {th }}$ September 2017 in two different settings: Wukro town and Mekelle city. The research received the full ethical approval from the Queen Margaret University Ethics Committee in Edinburgh (UK), and official support letters from Women's Affairs governmental offices in the aforementioned settings and the University of Mekelle, in Tigray (Ethiopia).

The recruitment process for the study had two phases: the first, in Wukro and the second, in Mekelle. In Wukro, two governmental Women Affairs office experts, both males and with relative long experience (at least five years) in implementing and monitoring women's development programmes, helped to recruit participants who met the selection criteria. One of the officers identified three runaway girls who lived in Wukro from a cohort of young students who were receiving financial support for their studies. He contacted each of them by phone and, after explaining the purpose of the research and ensuring confidentiality, he invited them to take part in the research and be interviewed in their own language (Trigrinya) by the first author with assistance from an interpreter.

In Mekelle, the local NGO Mums for Mums, which supports non-married young mothers, helped to recruit three more runaway girls living in the city. A social worker from this organization first contacted potential participants who met the above selection criteria by phone and then met them in person. Another participant, and the only girl who 
eloped for love, was recruited through the Women's Association of Tigray (WAT), an influential NGO that organises approximately 700,000 women in Tigray. This girl was a relative of one member of this association. In total seven girls who ran away or eloped were interviewed.

An appropriate sample size for a qualitative study is one that adequately answers the research question. In practice, a sample size in qualitative research usually becomes clear as the study progresses as new categories, themes or explanations stop emerging from the data (Marshall, 1996). Despite the limited time and resources for this study, the detailed accounts provided by the eloping girl and the six runaway girls in the ethnographic interviews provided adequate answers to the research questions. The first author observed data saturation once the interviews with the six runaway girls were completed.

As mentioned above, the second cohort of older women participants were recruited in Wukro and Mekelle through the snowball technique. Women's Affairs officers and the WAT supported this second recruitment process. Members of these institutions knew women married at an early age $(<16$ years old) and those women who agreed to be interviewed referred us to other women with the same characteristics. A total of six older women married at an early age were interviewed.

Additionally, the interviewed older participants were invited to take part in a focus group discussion (FGD) and encouraged to invite other older women ( $>26$ years old) who were also married at an early age. In the only FGD conducted during the research fieldwork, a total of six women participated in the discussion addressing female adolescent runaways and child marriages, among other topics. Two women were born in Mekelle city and the rest of the participants were from rural areas living in Mekelle (ruralto-urban migrants).

The data was collected in different settings, always guaranteeing the safety and most convenient time and location for participants. The interviews with the seven younger participants were conducted in secure and private closed rooms provided by the governmental department of Women's Affairs in Wukro and the NGO Mums for Mums in Mekelle. Most of the interviews with the older participants were conducted in a natural setting (their workplace), in order to minimise inconveniences. The WAT supported us with the logistics for the focus group discussion, providing a private and convenient place for the participants.

The first author conducted the interviews and focus group with an interpreter who was a female university student (Masters in Gender and Development at Mekelle University) 
fluent in English and Tigrinya and fully briefed on the purpose of the study. Before each interview, the interpreter wrote to and orally informed participants about the objectives of the research and assured anonymity and confidentiality. Additionally, it was made clear to participants that they were not under any obligation to take part in the research and that they could withdraw or stop the interviews if they felt the need to at any time. This was also emphasized in both the information sheet and the consent form. Interviews and the FGD were carried out after the participants had agreed and signed the consent form in their local language, Tigrinya, and English.

A semi-structured interview guide with open-ended questions was used for both the interviews and the FGD. The interview guide was structured in three parts. The first part (prior to running away) focused on socio-demographic data and family context, and specific questions regarding roles and parental relationships were posed. The second part of the interviews (running away) explored why and how these girls ran away from home. To do so, the research team explored aspirations and ideals of the girls and their knowledge about the new Family Law in Ethiopia. They also captured their stories, feelings and reflections on arranged marriage, and how they escaped from home. Additionally, the research team captured descriptions of the very first days after running away, posing questions such as 'Where did you go to ask for help?', 'How did you manage to find support?' and 'What was the reaction of your parents?' to elicit further details. The third part of the interview (after running away) sought primarily to explore the longer-term implications of the decision to escape in the girls' lives. Questions also included asking about the situation of the young participants at the time of the interview such as 'Do you live alone at the moment?', 'How do you make a living?' and 'Are you attending school?'.

The FGD guide sought mainly to examine how communities respond to adolescent female runaways, including questions focused on the older women participants' perceptions and attitudes toward runaway and eloping girls, as well as early arranged marriage (e.g. 'What would you do if your daughter is in love with a man who you do not accept?', 'Why do you think young girls decide to escape from home?', 'Is escape from home a good option?', etc.).

\section{Data analysis}


Data analysis followed the conventional thematic analysis approach using the method suggested by Graneheim \& Lundman (2004) and following the steps proposed by Nowell, Norris, White, \& Moules (2017). This was in order to increase trustworthiness during the data analysis process. Briefing sessions with the interpreter were held prior to the interviews to explain the objectives of the study and to mutually agree the meanings of key concepts such as adolescent, elopement and runaway, and other issues related to early marriage in Ethiopia. After each interview, the interpreter and researcher held a short debriefing to discuss and identify patterns and key answers of participants linked to the research questions, and to make sure the accounts were well understood by the researcher. The interviews and the focus group discussion with the participants were recorded with a digital audio-recorder and a digital camera respectively, and the transcriptions were made and transferred to a laptop by the interpreter directly into English. This was to provide as precise a version of what was said during the interviews as possible.

Furthermore, the analysis was conducted by the two authors through peer debriefing and researcher triangulation in order to establish trustworthiness. First, all the interview transcripts were read several times so that the researchers could familiarize themselves with the data. Alongside the transcripts, the first author triangulated the data from the interviews, focus group, field notes and reflexive journal notes, which helped the researchers to systemize, relate and cross reference data (Nowell et al., 2017). Persistent observation and engagement with local women was also relevant in the data analysis process.

Second, each transcript was carefully reread and hand coded, using open and in vivo coding techniques to identify initial themes and ideas. Third, data collected from other methods, such as group discussion and field notes, were first analysed separately and, second, integrated into an only coding framework. The themes that emerged were compared according to similarities and differences and grouped into 20 key categories. The fourth step was conducted by the two authors jointly. They revised these categories and then, through a selective coding process, classified them into appropriate themes, seeking to present a clear, coherent and complete framework of the findings. The research questions informed the data analysis process, which was also influenced by structuration theory (Giddens, 1984), allowing the analysis of individual factors as well as structural factors in influencing the decisions of girls to run away from home. Since adolescent runaways are an understudied phenomena in this specific research setting, the authors combined inductive and deductive approaches for data analysis. They identified patterns 
that are beyond the mere interview guide questions and are common to other countries (e.g. USA, Asia), such as poor parent-child relationship and child abuse and neglect.

Rich descriptions of the participants' experiences regarding this complex social phenomena are provided in order to answer the research questions. However, behaviours and contexts between different generations of women were also contrasted through examining community attitudes toward runaways, as well comparing individual participants' answers.

\section{Ethics}

A few ethical concerns were identified prior to the fieldwork. Due to the sensitive and secret nature of adolescent female runaways, and the fact that Family Law in Ethiopia bans underage marriages, there was a concern regarding the legal and social (stigma) consequences of disclosure of personal experiences.

To address this issue, anonymity and confidentiality were ensured during the whole research process. As mentioned above, before starting the fieldwork, the researcher (first author) offered the interpreter an inductive session on the research process to ensure that the confidential nature of the interviews and FGD was understood. The interpreter fully committed to ensuring confidentiality of all participants. Additionally, anonymity was ensured through encrypting participants' personal details such as names and addresses, with codes created by the researcher.

\section{Findings}

The findings of the study focus primarily on seven cases of girls who ran away from home to escape arranged marriages, except one who eloped with her boyfriend. The fact that it was difficult to identify cases of elopements could mean that 'romantic' elopements might not be as relevant in the context of Tigray (Ethiopia) as in Asian countries (Ahearn, 2004; Allendorf, 2013; Hart, 2010; Marsden, 2007). Elopements for love are also not socially accepted, as they may be considered 'shameful' premarital relationships. Moreover, they are associated with prostitution and immoral behaviors. Elopements are, therefore, hidden and difficult to identify. Due to the secrecy surrounding runaways, it was also difficult to reach runaway girls. The results that emerged from the data analysis suggest individual and structural factors influencing girls' decisions to run away, as will 
be now described.

\section{Family circumstances prior to running away}

Data analysis led us to conclude that family context is relevant when studying female runaways in Tigray. There are various family factors influencing the decision of the girl participants to escape from home. These include an excessive burden of domestic chores, absence of one of the parents, authoritative fathers and parental confrontation against the imposition of arranged marriages leading in some cases to violent situations.

Excessive domestic work and orphanhood. Four of the seven adolescent girls interviewed happened to be the oldest sibling, which in this specific rural context means that they have greater responsibilities at home than their younger brothers and sisters when their parents are absent working in the field. They are usually responsible not only for domestic chores such as cooking and taking care of their younger siblings, but also helping with the harvest, fetching water and tending the herd of oxen, among other tasks. Participants reported that they felt overworked when they lived with their parents. Genet (all names are pseudonyms), an 18-year-old girl who ran away from home when she was 14 , described the everyday tasks that she used to be assigned when living with her parents in the village in the following way:

"My parents were farmers, so they spent their days in the fields. I was the oldest daughter, so the domestic work was my responsibility in their absence. Yes. I felt overworked. I used to cook, fetch water, tend our herd of oxen, and I also took care of my younger siblings. I never allowed them to work, because I wanted them to focus on school. Even some times I helped my parents in the fields".

While the above list of tasks for girls is not unusual for girls in rural Ethiopia, the girls described the burden of domestic chores as excessive and over and above that normally expected in households, suggesting that exploitative elders and the burden of so many domestic responsibilities might have contributed to the decision to flee.

Secondly, four out of seven girls lost a parent during their childhood. In most cases it was the father, and in one case the mother. This has further relevance as the father and mother have different roles regarding children's care and education in Ethiopian culture and subsequently have differing impacts on the life of an adolescent girl. While the father was commonly the primary decision-maker and responsible for maintaining discipline within the household, the mother was seen by adolescent participants as have a more 
supportive role: "She sacrificed a lot for us (...) Even I refused to get married; my mother was supportive compared to the rest of my family" (Meseret, aged 17, ran away at 13 years old).

As is narrated by Meseret, the rest of the young female participants from both, rural and urban areas, also referred to their mothers as supportive, which may indicate that the mother-daughter bond is the strongest within the family in this context. Medhin was the only participant who eloped from the family home for love at the age of 16 and went to live with her boyfriend. She claimed that it was an "immature" decision and that she would have made a different decision if her mother had been alive when she eloped:

"I wouldn't be in a mess, if she (mother) was alive. I would have shared all my thoughts with her and she would have given me so much advice. Your mother is your confidante. You wouldn't feel comfortable telling your brother or father about things like this (dating)" (Medhin, aged 22, eloped at 16 years old).

Older female participants recalled their past lives in the rural villages, and their narratives contrasted with the 'open' mother-daughter relationship that Medhin constructed around her deceased mother. For instance, Fetle, a 38-year-old woman married at the age of 17, described how in the past "it was a shame to tell your parents anything like that (dating). You didn't talk to them about any relationship. They would scold you".

The absence of the father was seen by the community as leading to a lack of discipline within the household and, therefore, a factor that led one of the participants to refuse marriage and subsequently escape from home. This is in the case of Meseret, who also ran away at the age of 13 to escape an arranged marriage. However, the community in her village linked her decision to a lack of discipline due to her father's death and blamed her for having a premarital relationship:

"When I refused (marriage), everyone thought it was because I already had a boyfriend. They said it was because my mother raised me on her own and because of the death of my father that I lacked discipline" (Meseret, aged 17, ran away at 13 years old).

In Ethiopian culture, the father figure represents discipline and strictness. Fear was the feeling most often mentioned when asked about the relationship with their father, whereas they said they felt closer to their mother:

"I was afraid of him (...). He threatens us and gets angry (...). Well, we used to talk, but I was afraid of him because he gets very scary when he is angry. So we were closer to our mother" (Faven, aged 20, ran away at 13 years old).

“Back in my days, family dominated every decision, you didn't make any decision by 
yourself' (Meaza, aged 36, married at 15 years old).

Imposition of arranged marriages. Ethiopian Family Law bans underage marriage and emphasizes the "free and full consent" of spouses since 2000. However, despite the Government of Ethiopia being one of the first to launch the African Union (AU) Campaign to End Child Marriage in 2014, arranged early marriage is still being practiced in rural areas of Tigray without the consent of young girls. Sometimes this happens with the complicity of community leaders and the protection committees set up to prevent this from happening, as this key informant disclosed:

"Some people are in the early marriage committees but they are not doing good work because the perpetrators or the families that arrange child marriages are relatives of 'kebele' (district) leaders, so they don't want to punish them" (GBV expert of UNFPA in Tigray, Mekelle).

As this key informant recognizes, arranged early marriages are still practiced in rural Tigray despite the law, and it seems that younger and older generations of women have not had a say in the marriage arrangements. In all cases, the father's role and authority was explicit in the participants' narratives:

"I told him I didn't want to get married, but he said I had to do what he said because he's the father" (Mariam, aged 17, ran away at 15 years old).

"I never tried to oppose the wedding, because no one listened to you, so I never confronted my parents directly, because if your mum or your dad told you to do something, even if it was falling from a cliff, you did it" (Tirhas, aged 38, married at 13 years old).

When both runaway girls and older married women knew about their arranged marriage, confusion and surprise were followed by fear, as is described by participants:

"He (father) was acting very strange by being nice to me. He started spoiling me (...), he started to buy me clothes and other things to make me stay home which got me suspicious" (Mariam, aged 17, ran away at 15 years old).

As this young participant reveals, the way adolescent girls discovered the arranged marriage might suggest that parents were worried about girls running away and therefore kept the wedding secret.

Threats and child maltreatment. Despite the authoritative approach and the fear described above by the young participants, all of them in one way or another resisted their parents' decision to marry them off. The situation of the girls at home often deteriorated after they refused to marry, and some of them reported maltreatment such as beating and abandonment. In most cases, the parents' reaction was to ignore their daughters' will and, 
in some cases, parental confrontation led to violent situations where some girls reported death threats and beatings:

"She (mother) told me my father would kill me (if I refused to marry). And I told her he won't find me and so that she should worry about herself' (Genet, aged 18, ran away at 14 years old).

"My father's brother (her father died) beat me up so badly trying to get me to give up on my dreams but I told him he could kill me if he wants and that I'd rather die than get married" (Meseret, aged 17, ran away at 13 years old).

The maltreatment suffered by the girl participants included abandonment and being neglected by their father, "he stopped buying me clothes and other things", reported Mariam (aged 17, ran away at 13 years old), who emphasized that she had "no option" but to escape to her aunt's house.

\section{Decision to run away}

Two major themes emerged from the narratives of the young participants regarding how they ran away from home. Firstly, the decision to run away was, in most cases, influenced by emotions. Secondly, they escaped secretly and alone. However, after running away, many of them were supported by relatives and neighbours for at least the first year.

Context prior to running away. The six runaway cases and the elopement analysed in the study show that some of the girls did not plan to escape in advance. In some cases, girls left home almost immediately after finding out their arranged wedding date such as the day after. In other cases, the adolescents only waited a few days in order to collect some cash. Feelings of anger and sorrow preceded the decision to escape:

"She (mother) said that I can't go, that I would be married soon because my father agreed, so no more school for me. That same night I cried myself to sleep. The next day, it was a Saturday, after my parents went out to the farm, I collected all my clothes and my school documents in a plastic bag and left the house" (Genet, aged 18, ran away at 14 years old).

A tense environment also preceded the impulsive decision of Medhin to elope. She described the constant arguments with her brother about her 'romantic' relationship with a man ten years her senior, and she narrated that during one of these quarrels she left her brother's house in order to go and live with her boyfriend. 
The fact that the girls claimed not to have thought of leaving their families seems to be consistent with the emotionally driven nature of their decision to run away. For all runaway participants, it was the first time they had ever escaped from home. However most of them had previously heard about other runaway girls in their rural villages, so the decision to escape might not have been entirely spontaneous but perhaps something they had previously considered.

Secret escapes and support after running away. The runaway girls of the study in Tigray escaped secretly, "I made sure no one was watching, grabbed my clothes and left the house", narrated Faven (aged 20, ran away at 13 years old), who said she had not had contact with her father since she ran away seven years ago. The participants' unwillingness to divulge details indicated the girls' fear of discovery. If they were found by their father, they might have been taken back home and eventually married off.

There is another common and relevant pattern in the runaway cases explored in this study. In all cases the adolescents left home on their own and, except for two cases, all girls were supported by relatives who hosted them and paid their expenses for at least the first year after they left the parental home. These included an older brother, a male cousin, or an aunt, who in some cases even acted as an accomplice by hiding the runaway girl from her father, as Mariam disclosed: “After I ran away, whenever he (father) came to my aunt's house to take me back she'd tell him that I wasn't at home. (Mariam, aged 17, ran away at 15 years old). In some cases, neighbours also helped runaway girls, as one older woman narrated:

"I know a girl that ran away from her village to escape arranged marriage. She was my mother's old neighbour's daughter. She ran away and came to Mekelle. She was about 12. After she came to our house, and told my mother what happened, we decided to let her stay with us" (Participant in the Focus Group Discussion).

\section{Determinants of female adolescent runaways in Tigray}

The imposition of an arranged marriage was, as mentioned above, the immediate trigger for the decision to run away among most adolescent girls who took part in this study. Only one 'romantic' elopement was identified during the fieldwork. While this is a small study and is in no way representative of the reasons why all girls run away, some themes emerged from data analysis. These included personal motivations related to education and 
employment, changing social norms regarding marriage decision-making and knowledge about girls' rights.

Personal aspirations. In the narratives of runaway adolescent girls who escaped arranged marriage, the impulse to run away was enhanced in most cases by a strong personal motivation to continue education up to university level if possible. All participants considered education highly valuable for themselves and their daughters, and the only accessible means for obtaining a "better life" and leaving behind the harsh conditions of rural existence:

"I didn't want to get married, I only wanted to continue with my education (...) I am happy with my decision (to run away). I have a better life here (in Wukro town). Just because I am here, I get exposure to many things I didn't know existed back when I was in the village" (Tsega, aged 16, ran away at 15 years old).

The findings seem to suggest that currently younger generations of women have more opportunities (e.g. education, employment) than previous generations. In turn, this may have triggered the personal aspirations of girls to be educated and financially "independent". Indeed, when adolescent participants were asked questions relating to the ideal time for marriage rather than a specific legal marriageable age, most of them considered that a woman should be "educated and independent" before considering it:

"I'd say independence is a very important factor when you think about marriage. The woman has to be able to compete with the man at least financially. This would balance the decision-making power in the house. I don't think it's a good idea to get married when you have nothing just because you are 18" (Meseret, aged 17).

"Education is very important. You should be independent because being dependent on someone has its own challenges. You should be strong enough to support yourself at times when he (husband) says he'll leave you. You wouldn't panic because you can't support yourself" (Medhin, aged 22).

These personal motivations to be "educated and financially independent" are sometimes reinforced by older generations of women living in urban areas and who have suffered the consequences of arranged marriages. Meaza defended this idea in the following way:

"I know what it is like to be forced to marry someone you don't want, and I don't want my daughter to go through that (...) I think it is very important for a girl to be educated and have her own thing as well, so if the guy really wants to marry her, he should be able to wait for her until she finishes her education" (Meaza, aged 36, married at 15 years old). 
These individual point of views and positions must be contextualized in relation to the influence of the Women's Association of Tigray (WAT). It is noteworthy that many young and older women in Tigray respect and support WAT, an influential local women's NGO which was founded by female fighters of the Tigray People's Liberation Front (TPLF) during the struggle in 1977. They had an important advocacy role in demanding women's rights, such as equal education and opportunities for girls (Mjaaland, 2013, 2016). The social legacy of WAT might also be an influential factor on girls' decisions to escape arranged marriage and it might be feeding these personal aspirations to be educated and independent.

Changing social norms. The findings also suggest the interplay between the above individual motivations and beliefs, and changing social norms. For instance, regarding marriage decision-making such as marriage timing and mate choice, which might also influence the decision of girl participants to run away from home.

With regards to marriage timing, although early marriage is still practiced in rural areas, both older and younger participants in this study rejected the parental decision to marry them off at an early age, which might further point to a shift in traditional norms. However, older participants may have been affected by a degree of social desirability bias with the intention of presenting themselves as progressive and law-abiding to the researcher. They described how in the past arranged early marriage was socially accepted and how nowadays not only do they condemn it, but also link self-choice marriages at an older age as a "modern" behaviour.

The Gender and Development expert interviewed suggested that currently young people marry later and that some of them even decide not to get married but to live together. This usually occurs in urban areas and in secrecy. "Marriage is not now as important as before; now young people are living without marriage. Some girls, even in their 30s, they don't care about marriage (...) Behaviours are changing from time to time", emphasized the Gender and Development lecturer (University of Mekelle).

Better informed about their rights. It seems that institutional decisions (e.g. new family and marriage legislation) might also be triggering new social behaviours and might even have influenced the decision of girls in this study to run away. Data from field observation and interviews with key informants reveal that the Ethiopian Family Law and the strong national campaign against child marriage have not only decreased the prevalence of child marriage in Tigray, but have also led to a better understanding about the consequences of early marriage among rural communities. The girls are better informed 
about their rights than previous generations of women, and in particular about the required "full and informed consent" of spouses, as propagated by the child marriage committees in schools and youth clubs.

"Because now they are exposed to more information and even in the school they are discouraging early marriage (...) So they know they have an option to escape those early marriages. They have heard a lot of things in the school, in the social mobilizations, in other awareness activities, so they know about this. So they feel more empowered and protected by the law, and they can be more active even to respond and talk to their parents and claim their right not to be married under 18" (Gender and Development lecturer, University of Mekelle).

Consequently, campaigns throughout schools, local women organizations and international programs might also have had an impact on young people, driving this generation of girls to express new social values and challenge some traditional gender roles for the first time.

\section{Implications of running away}

The data analysis allowed us to identify relevant implications of the decision to run away for the young female participants' lives. Social stigma, dropping out school, early and unwanted pregnancies, transactional sex relationships and higher risk of child trafficking were some of the consequences identified, as explained below.

Community response: double moral standard and stigma. A major theme identified during the data analysis process was the double moral standard with which the community approached adolescent runaways in the research setting depending on the motivations behind such a decision. All participants, except for one woman from the older cohort, considered the decision of girls to run away as legitimate and the only option to avoid the imposition of an early marriage. However, elopements for love were linked to 'immoral' acts such as prostitution and addiction by some participants. Indeed, some considered elopements a deviant behaviour which could lead girls to a life of hardship and abuse, as described below:

"Usually they are very young when they make such decisions and it is usually with the wrong boys. The stories I hear of such cases are of girls who are too young to even be dating. The boys always end up mistreating them" (Gidena, aged 41, married at 15 years old). 
Regardless of the reason behind the decision to escape, runaway adolescent girls seemed to be judged harshly in rural communities. Younger and older participants provided some accounts in relation to this:

"The problem is, when a girl runs away or goes to the city, the people in our village have the assumption that she is there not to improve her life, but to whore around or engage in immoral acts" (Genet, aged 18, ran away at 14 years old).

"Mostly when girls run away, they get raped, become dependent on someone and addicted to so many things, like alcohol, drugs" (Gidena, aged 41, married at 15 years old).

"I know girls who run away from their villages and became prostitutes here and some live here with their boyfriends" (Abeba, aged 20, ran away at 14 years old).

In addition to the above double moral standard and judgements within rural communities, social stigma was also identified in urban areas. Medhin reported her experience of such stigma in relation to dating an older man against her father's will, marrying him and then becoming a young divorcee.

Transactional sex and early pregnancies. Some studies on adolescent female runaways conclude that runaway girls are exposed to a higher risk of sexual exploitation (Raval et al., 2010; Sharp, 2015; Tyler et al., 2001). In this specific study, a key informant corroborated this in the following way:

"They have no money, and they have to work, especially those girls from poor families, they are very young, but they have to work, and the thing is that in many cases when girls don't pass grade 11, they are directly engaged in coffee houses; prostitution" (Gender and Development lecturer, University of Mekelle).

Although most girls are supported by relatives after running away, the protective role and control of the parents over girls' lives is not the same when living with relatives. The case of Abeba is illustrative of this. She disclosed that she was involved in a transactional sex relationship. She ran away from her family home to escape marriage when she was 14 and went to live with her aunt in the city. Since she had to take care of her aunt's children, she used to attend night school. She began a secret relationship with a classmate and got pregnant, so she had to leave her aunt's house as well. By the time of the interview, Abeba was 20 years old and she was living by herself and raising her son alone. She worked in a coffee shop and had occasional sex with a man who supported both her and her son economically, because as she argued, to "raise a baby alone is tough".

Labour exploitation and dropping out of school. The decision of girls to run away from home implies a jump into adult life and into a completely new urban environment. 
Participants reported the challenges they faced after running away from rural areas and how vulnerable they were to exploitation:

"It was very challenging. I grew up in the village, so I didn't know anything about city life. I already used to work in the house but having to work for people other than your family is very different. The people just want to exploit you. You can't do whatever you like whenever you like. The household work just never seems to end. You clean house, cook, wash clothes, and by the time it's night time, you can't even read because they (employers) complain about the light" (Genet, aged 18, ran away at 14 years old).

After a while, Genet left this exploitative work situation and became a construction worker. She combined work and studies, like other young participants. In fact, at least three runaway girls interviewed for this study reported skipping school to go to work, which may explain why Genet did not get high enough grades to access university, like many other girls with low paid work in Tigray.

The fact that some young runaway participants were supported by their aunt or brother does not necessarily imply that they were in a much better position. According to the data, most girls who were supported by family members had to do domestic chores, take care of children, and some of them worked outside the house too, as Faven (aged 20, ran away at 13 years old) described: "My brother pays for my expenses. But when I get the opportunity I work as a cleaner in people's houses. I help my brother with the house chores too". Consequently, some participants usually went to school in the evening and some of them ended up dropping out of school.

Migration to urban areas and neighbouring countries. Finally, as a key informant reported: "Many girls migrate to Saudi Arabia for different reasons, including that (to escape arranged marriages)" (SGBV expert of UNPFA in Tigray). One of the young participants described how she met a person who proposed that she illegally migrate to Saudi Arabia. This reflects that illegal channels of migration are more accessible nowadays to the Ethiopian youth than in the past and, consequently, these vulnerable runaway girls may be exposed to a higher risk of child trafficking in this country.

Furthermore, female adolescent runaways are also associated with rural-urban migration. In some studies, rural girls who escaped arranged marriage in Ethiopia are treated as migrants who ran away to towns and cities searching for education and jobs to improve their lives (Erulkar et al., 2007; Erulkar \& Muthengi, 2009).

\section{Discussion}


This study explores individual factors (e.g. family circumstances and personal aspirations) and structural determinants (e.g. Family Law and governmental campaigns) influencing the seven adolescent participants' decision to escape from home. The findings show common factors between high and low income countries, such as poor daughterparent relationships, parental authority and abuse, leading adolescents to run away from home. However, there are unique social determinants and implications in resource-poor settings for runaway girls. The young female participants in this study escaped from the imposition of an arranged marriage, but they also ran away from parental authority and, in some cases, from experiences of abuse and neglect within household. This confirms that adolescent runaways are a multidimensional and complex phenomena.

\section{Individual factors}

The girls of this study partially challenged the norms assigned to their gender, in particular those customary norms related to the age at which a woman is supposed to become a housewife and mother in the rural context of Tigray. Consistent with the ethnographies conducted by Mjaaland $(2004,2013,2016)$ in the same region, the findings of this study suggest that six out of seven girl participants made a strategic decision when they escaped, prioritizing their education over their family's decision to marry them off. In the interviews, girls considered education as the primary means to get a "better" job that would provide them with their own incomes. Through this, they would gain financial independence and ultimately more decision-making power within the household, as explicitly stated by some participants.

Through the lens of the structuration theory (Giddens, 1984), we observed how early marriage is a traditional practice that has been reproduced generation by generation in rural Tigray as in other African settings, as described in the narratives of both older and younger generations. However, while most of the older participants did not resist their parents' decision to marry them off at an early age, the adolescent girls of the study behaved differently by running away from home, even though the socioeconomic (e.g. poverty) and family contexts (e.g. parental authority) of both cohorts of participants were apparently similar.

Social change usually refers to any significant alteration over time in behavior patterns and cultural values and norms. We cannot conclude that the so-called 'deviant' behaviors 
of the younger participants of the study are a definite reflection of a wider social change. However, the findings of the research provide some indications of a potential shift in social norms that affect women's marriage patterns in Tigray, Ethiopia. This appears to follow a trend in other countries in Africa, such as Malawi (Bertrand-Dansereau \& Clark, 2016), where young women have a say in marital decision-making.

The runaway girls in this study also challenged parental authority, specifically the 'father figure', who is the decision-maker and highly respected in the patriarchal system dominant in Ethiopia. This cultural phenomenon has been explored in other investigations based in Latin American countries, for instance, by Kathryn A. Sloan (2008) in her book 'Runaway Daughters' in Mexico.

Finally, the young female participants resisted the rural tradition to marry at an early age, in line with other research on marriage related decision-making in India (Bhakat, 2015). However, consistent with Ahearn (2004), this does not mean that the participants rejected all socially prescribed gender roles. All of them expressed their desire to have children, more specifically between 4 and 5 children, as having children provides a sense of security to mothers and is highly valued in Ethiopian culture. As Molla (2018) points out, having children in Ethiopia is considered a "source of blessing" for the family, rather than a responsibility. This has relevant implications as addressed further on. In sum, girls are challenging parental authority, but at the same time they are reproducing social norms, or in more concrete terms, the gender roles and responsibilities associated with having and rearing children.

\section{Structural factors}

The findings of this study might suggest, on the one hand, that the runaway participants' behavior was influenced by social structures, such as institutional rules (e.g. Ethiopian Family Law) and governmental and international organizations' campaigns against early marriage (Mekonnen \& Aspen, 2009; United Nations Population Fund [UNFPA], 2008). These would have facilitated the girls' awareness of their rights and influenced their decisions to act accordingly. This conclusion seems consistent with other studies addressing transitions from traditional arranged marriage to self-choice marriage and the influence of the globalization of Western ideals and behaviors on marriage patterns (Allendorf, 2013). Moreover, their decisions also seem to have been influenced by the 
into marriage at an early age and who now defend the decision of adolescents to escape marriage. This is consistent with Giddens' structuration theory, which suggests that human agents act and interact in social contexts, thereby influencing each other in relation to decisions and behaviors. Through doing so, they reproduce or change social structures, such as traditions, moral codes, and other established ways of doing things. In this case, customary early-arranged marriage is being challenged.

Consistent with Allendorf (2013), who points to the expansion of education as an important factor with regard to elopements in India, in the context of Tigray the adolescent runaway participants had higher education levels than the older participants, which might explain why they behaved differently. Younger generations of girls may have felt more confident and knowledgeable than their older counterparts in resisting parental decisions and even confronting their fathers.

Other external factors that might explain differences between younger and older participants could be a result of historical factors such as the fact that older women experienced long periods of war and oppression, with few options outside marriage except to join the struggle. As Mjaaland (2013) narrates, many of the female fighters in the 1970 and 1980s joined the struggle to avoid arranged early marriage and liberate themselves from the 'double' oppression by men and the Derg regime. In contrast, nowadays Ethiopia is a relatively stable country with rapid and improving economic growth, which might result in greater opportunities for younger females, and a stronger position for them to exercise their agency in making decisions like running away from home. That said, we must note that unemployment continues to be high among female and male youth despite Ethiopia's impressive economic growth rate over the past decade.

\section{Social construction of female adolescent runaways}

On the one hand, adolescent runaways from arranged marriages are considered as an unfortunate consequence of a harmful traditional practice (early marriage) by the women and girls who participated in this study, and as a deviant behavior or an act of rebellion against early marriage by rural communities. On the other hand, adolescent female runaways are seen as a contributing factor to high rural to urban migration. This is consistent with migration studies which include girls who escape arranged marriages in the statistics of the rural-urban migration phenomena (Erulkar et al., 2007; Erulkar \& Muthengi, 2009; Terefe et al., 2015; Van Blerk, 2007). 
The findings of this small study suggest that female adolescent runaways are often seen as a relatively commonplace phenomenon in these communities, which may result in these girls being unprotected. There are different reasons which may explain why this phenomenon is overlooked in this context. Firstly, most of the runaway girls in this study had temporary support from relatives and neighbors. Additionally, in most cases parents did not report the runaways to the police and did not insist on returning their daughters back home, as they may have believed they were safe. Secondly, in the case of runaways for love (elopements), these individual cases might be ignored or hidden. This is because they are constructed as 'mistakes' and linked to immoral acts, such as prostitution and addictions, as is shown in other contexts such as the USA (Staller, 2003). And thirdly, adolescent female runaways are associated with a migration-related decision, which seems to be socially accepted. This also historically occurred in the USA, for instance, when children left home at ages 10 to 14 to work as laborers (Schaffner, 1999). The social construction of female adolescent runaways as a migration-related issue is demonstrated, for example, by a study conducted by some local institutions in Tigray on early marriage and other Harmful Traditional Practices (HTP). This study concludes that early marriage “exacerbates urban migration" (Terefe et al., 2015), as girls "migrate” to escape arranged marriages.

\section{Child care and girls' ${ }^{\prime}$ resilience in Ethiopia}

The fact that female adolescent runaways may be considered a normal phenomenon among the communities in Tigray might explain the lack of social structures to protect them in spite of their vulnerabilities. For example, they are exposed to a range of risks, such as early and unwanted pregnancies, labor exploitation, dropping out of school, and transactional sex, as suggested in this study and as is consistent with other studies in the same field (Raval et al., 2010; Sharp, 2015). Indeed, a deeper analysis of the context would be needed to discuss why public institutions and communities overlook the needs of these underage runaway girls who often live alone. For instance, in the case of this study, four out of seven were living alone at a young age without an adult present.

Molla (2018), an author on childhood and care models in Ethiopia, points out that risks can only be understood as part of the larger social, economic, political, traditional, religious, sexual, patriarchal, and cultural systems and webs that contribute to risk for children. Firstly, she observes that the Ethiopian community does not question its social, 
traditional and religious values and norms that put children at risk due to early marriage and other customary practices. For instance, women's primary role is perceived as that of reproduction and, as mentioned above, having children is primarily seen as "source of blessing" for the family, rather than as a burden or responsibility. Secondly, she questions the child care-giving models adopted by international non-governmental organizations (INGOs) in Ethiopia for being non-contextual without considering the particular realities of children in Ethiopia. In addition, she points out that the INGOs do not make the communities responsible for being care agents of their children and proposes a holistic childcare model, which makes communities and institutions act as direct care agents of their children.

The influence of social norms and community attitudes towards runaway girls in Ethiopia is consistent with another study on young female survivors of sexual violence in northern Uganda (Stark, Landis, Thomson, \& Potts, 2016) which also addresses child protection and community responses toward at-risk girls. In this study, social norms and communal attitudes emerge as powerful forces that influence the level of support provided by caregivers, friends and the broader community to these at-risk girls. Stark, Landis, Thomson, and Potts (2016) emphasize the key role of informal actors, such as friends and relatives, and their ability to support girls' resilience. They propose, in line with Molla (2018), holistic interventions to address harmful social norms and attitudes that contribute to social stigma against survivors of sexual violence or any other at-risk group of girls.

\section{Limitations of the study}

A limitation of this study is its small sample size. This is a direct result of the characteristics of the hard-to-reach population under study (runaway and eloping girls) and the limited resources and time available. However, we addressed this limitation through conducting in-depth qualitative interviews and capturing detailed accounts that answered the research questions posed. In addition, we focused only on the Christian Orthodox population, which is the majority religion practiced in Tigray $(95.6 \%$ of the population selfidentify as Orthodox) (CSA, 2007). The fact that we focused only on the majority religious community may have somewhat biased our findings.

Another limitation of the study in terms of validity may be a potential desirability bias, which refers to the tendency of research subjects to give socially desirable responses instead of choosing responses that are reflective of their true feelings. In this study, older 
female participants may have wished to present themselves as progressive and law-abiding. This may have manifested through statements rejecting arranged marriages and advocating for an approach that emphasises open communication with their daughters. We tried to minimize and identify this bias through data triangulation.

Finally, we must mention that the research team did not have the opportunity to share the synthesised findings with the participants for their comments. We believe that this would have enhanced the study findings as well as provided the participants with information on our findings. However, logistical considerations did not permit this.

\section{Conclusion}

In conclusion, all the points discussed above have shed light on the individual and structural factors influencing girls who run away from home in an understudied setting in Africa, such as Tigray (northern Ethiopia), a poor resource context, and explore the social and cultural construction of the phenomenon in this region. The study suggests that female adolescent runaways might be ignored or normalized within the community in Tigray. Different reasons may explain why this phenomenon is overlooked in this context, such as the fact that girls who run away from home to escape arranged marriage seem to be considered rural-to-urban migrants instead of at-risk girls who might require social protection and public health services. This study raises questions for further research and discussion, such as the need to examine female adolescent runaways from a policy level perspective and seeking to respond to key questions in addressing and preventing this issue in the context of eastern Africa: How are girl runaways classified at policy level in the regional context? Are girl runaways primarily a migration issue, a public health or social problem, or all of these? What is gained and/or lost through framing the issue in this light? What are the childcare models in place in Sub-Saharan African countries to protect these at-risk girls and how efficient are they?

Despite the small size of the study, this enquiry suggests that further research on this phenomenon and context is urgently needed to address both policies and service implementation that may respond to runaway girls' needs as defined by them.

\section{Declarations of interest}

The authors have no actual or potential conflicts of interest, or any financial, personal or other relationship relevant to this article to disclose. 


\section{Funding sources}

This study is funded by the Institute for Global Health and Development, at Queen Margaret University, Edinburgh, UK and Santander Bank. The funding body has had no involvement in the research or development of this manuscript.

\section{Acknowledgements}

We would like to thank the collaboration of all Ethiopian girls and women who took part in the research. We thank Prof Alastair Ager and Joanne Priest for their feedback and contributions to improve the manuscript.

\section{References}

Ahearn, L. M. (2004). Literacy, power and agency: love letters and development in Nepal. Language and Education, 18(4), 305-316.

Allendorf, K. (2013). Schemas of marital change: from arranged marriages to eloping for love. Journal of Marriage and Family, 75(2), 453-469.

Bhakat, P. (2015). Involvement of youth in marriage related decision making in India. European Scientific Journal, 1, 178-190.

Bertrand-Dansereau, A. \& Clark, S. (2016). Pragmatic tradition or romantic aspiration? The causes of impulsive marriage and early divorce among women in rural Malawi. Demographic Research, 35, 47-80. doi: 10.4054/DemRes.2016.35.3

Boyden, J., Pankhurst, A. \& Tafere, Y. (2012). Child protection and harmful traditional practices: female early marriage and genital modification in Ethiopia. Development in Practice, 22, 510-522. https://doi.org/10.1080/09614524.2012.672957.

Bryman, A. (2004). Social Research Methods. New York, USA: Oxford University.

Central Statistical Agency. (2007). Addis Ababa, Ethiopia.

Chuta, N. \& Morrow, V. (2015). Youth trajectories through work and marriage in rural Ethiopia. Oxford, UK: University of Oxford, Young Lives.

Creswell, J. W. (2008). Research Design: Qualitative, Quantitative, and Mixed Methods Approaches. London, UK: SAGE Publications.

Creswell, J. W. (2013). Qualitative Inquiry and Research Design: Choosing among Five Approaches. Thousand Oaks, Canada: SAGE Publications.

Ethiopia Demographic and Health Survey. (2016). Addis Ababa, Ethiopia. 
Erulkar A. S., Mekbib, T., Simie, N., \& Gulema, T. (2007). Migration and vulnerability among adolescents in slum areas of Addis Ababa, Ethiopia. Journal of Youth Studies, 9, 361-374. https://doi.org/10.1080/13676260600805697.

Erulkar A. S., \& Muthengi, E. (2009). Evaluation of Berhane Hewan: a programme to delay child marriage in rural Ethiopia. International Perspective on Sexual and Reproductive Health, 35(1), 6-14.

Ferguson, K. M. (2009). Exploring family environmental characteristics and multiple abuse experiences among homeless youth. Journal of Interpersonal Violence, 24, 1875-1891. https://doi.org/10.1177/0886260508325490

Giddens, A. (1984). The constitution of society: Outline of the theory of structuration. Cambridge, UK: Polity Press.

Goldstein, D. E. (2004). Once upon a virus: AIDS legends and vernacular risk perception. Logan, USA: Utah State University Press.

Graneheim, U. H., \& Lundman, B. (2004). Qualitative content analysis in nursing research: concepts, procedures and measures to achieve trustworthiness. Nurse Education Today, 24, 105-112. https://doi.org/10.1016/j.nedt.2003.10.001

Hart, K. (2010). The economy and morality of elopement in rural western Turkey. Ethnologia Europaea, 40(1), 58-76.

Marshall, M. N. (1996). Sampling for qualitative research. Family Practice, 13, 522-526. https://doi.org/10.1093/fampra/13.6.522

Marsden, M. (2007). Love and elopement in northern Pakistan. Journal of the Royal Anthropological Institute, 13, 91-108. https://doi.org/10.1111/j.14679655.2007.00415.x

Martinez, R. J. (2006). Understanding runaway teens. Journal of Child and Adolescent Psychiatric Nursing, 19, 77-88. https://doi.org/10.1111/j.1744-6171.2006.00049.x

Maxwell, J. A. (2013). Qualitative Research Design: An interactive Approach. Thousand Oaks, Canada: SAGE Publications.

Mekonnen, B. M., \& Aspen, H. (2009). Early marriage and the campaign against it in Ethiopia. In S. Ege, H. Aspen, B. Teferra, \& S. Bekele (Eds). Proceedings of the $16^{\text {th }}$ International Conference of Ethiopian Studies, Trondheim, Norway.

Mjaaland, T. (2004). Beyond the coffee ceremony: women's agency in western Tigray, northern Ethiopia. Betwixt \& Between: sosialantropologistudentenes tidsskrift. 
Mjaaland, T. (2013). At the frontiers of change? Women and girls' pursuit of education in north-western Tigray, Ethiopia (Doctoral dissertation). Retrieved from Bora Home, University of Bergen, Norway.

Mjaaland, T. (2016). Negotiating gender norms in the context of equal access to education in north-western Tigray, Ethiopia. Gender and Education, 30, 139-155. https://doi.org/10.1080/09540253.2016.1175550

Molla, R. S. (2018). Pastoral care in the living web for at-risk children in Ethiopia. Journal of Pastoral Theology, 28, 189-202. doi: 10.1080/10649867.2018.1547957

Moskowitz, A., Stein, J. A., \& Lighfoot, M. (2013). The mediating roles of stress and maladaptive behavior on self-harm and suicide attempts among runaway and homeless youth. Journal of Youth and Adolescence, 42, 1015-1027. doi: 10.1007/s 10964-0129793-4.

Murphy-Graham, E. \& Leal, G. (2015). Child marriage, agency, and schooling in rural Honduras. Comparative Education Review, 59(1), 24-49.

Nowell, L. S., Norris, J. M., White, D. E., \& Moules, N. J. (2017). Thematic analysis: Striving to meet the trustworthiness criteria. International Journal of Qualitative Methods, 16, 1-13. doi: 10.1177/1609406917733847

Pankhurst, A., Tiumelissan, A., \& Chuta, N. (2016). The interplay between community, household and child level influences on trajectories to early marriage in Ethiopia: Evidence from Young Lives. Oxford, UK: University of Oxford. Oxford Department of International Development (ODID).

Peled, E., \& Cohavi, A. (2009). The meaning of running away for girls. Child Abuse \& Neglect, 33, 739-749. https://doi.org/10.1016/j.chiabu.2007.04.018

Pelaez, S. (2012). Se la robaron (Elopement) in central Mexico: An ethnographic case study from Santiago Tlacotepec (Master's thesis). Retrieved from the University of Texas - Pan American.

Raval. V., Raval, P. H., \& Raj, S. P. (2010). Damned if they flee, doomed if they don't: narratives of runaway adolescent females from rural India. Journal of Family Violence, 25, 755-764. https://doi.org/10.1007/s10896-010-9333-5

Schaffner, L. (1999). Teenage Runaways: Broken Hearts and "Bad Attitudes". London, UK: Routledge. 
Schoen, R. F. (2015). Educated girls, absent grooms, and runaway brides: Narrating social change in rural Bangladesh. Forum Qualitative Sozialforschung / Forum: Qualitative Social Research, 16. http://dx.doi.org/10.17169/fqs-16.1.2178

Sharp, N. (2015). Keeping it from the community. Safer communities 14, 56-66. doi: 10.1108/SC-03-2015-0007

Sloan, K. A. (2008). Runaway daughters: seduction, elopement and honor in NineteenthCentury Mexico. Albuquerque: University of New Mexico Press.

Staller, K. M. (2003). Constructing the runaway youth problem: boy adventures to girl prostitutes, 1960-1978. Journal of Communication, 53, 330-346. https://doi.org/10.1111/j.1460-2466.2003.tb02594.x

Stark, L., Landis, D., Thomson, B., \& Potts, A. (2016). Navigating support, resilience, and care: Exploring the impact of informal social networks on the rehabilitation and care of young female survivors of sexual violence in northern Uganda. Peace and Conflict: Journal of Peace Psychology, 22, 217-225. http://dx.doi.org/10.1037/pac0000162 Advance on-line publication.

Stoebenau, K., Heise, L. Wamoyi, J. \& Bobrova, N. (2016). Revisiting the understanding of "transactional sex" in sub-Saharan Africa: a review and synthesis of the literature. Social Science \& Medicine, 168, 186-197. http://dx.doi.org/10.1016/j.socscimed.2016.09.023

Tadele G., \& Kifle, W. (2012). Chapter 2 Ethiopia. In J. J. Arnet (Eds.), Adolescent Psychology Around the World (pp. 15-27). New York, NY: Psychology Press.

Terefe, W., Desta, A., Alemayehu, M., Asmelash, A., Kifle, H., \& Gebre, F. (2015). Report on Baseline Assessment on Harmful Traditional Practices in five 'woredas' of North West and Western Zones of Tigray. Mekelle: Mums for Mums, Tigray Women's Affairs and Mekelle University, funded by Civil Society Support Program (CSSP).

Trotter, R. T. (2012). Qualitative research sample design and sample size: Resolving and unresolved issues and inferential imperatives. Preventive Medicine, 55, 398-400. doi:10.1016/j.ypmed.2012.07.003

Tyler, K., Whitbeck, L. B., Hoyt, D. R., \& Cauce, A. M. (2001). The effects of a high-risk environment on the sexual victimization of homeless and runaway youth. Violence and Victims, 16(4), 441-455.

United Nations Population Fund. (2008). Report on Activities Undertaken on "Stop Early Marriage” Campaign. Addis Ababa, Ethiopia: UNFPA. 
Van Blerk, L. (2007). AIDS, mobility and commercial sex in Ethiopia: implications for policy. Journal AIDS Care, 19, 79-86.

https://doi.org/10.1080/09540120600805091

Walker, J. A. (2012). Early marriage in Africa - Trends, harmful effects and interventions. African Journal of Reproductive Health, 16(2), 231-240. 